\title{
REVIEW ARTICLE
}

\section{Travelers' Diarrhea: A Clinical Review}

\section{BENTHAM}

\author{
Alexander K.C. Leung ${ }^{1,}$, , Amy A.M. Leung ${ }^{2}$, Alex H.C. Wong ${ }^{3}$ and Kam L. Hon ${ }^{4}$
}

${ }^{I}$ Department of Pediatrics, The University of Calgary, Alberta Children's Hospital, Calgary, Alberta, Canada; ${ }^{2}$ Department of Family Medicine, The University of Alberta, Edmonton, Alberta, Canada; ${ }^{3}$ Department of Family Medicine, The University of Calgary, Calgary, Alberta, Canada; ${ }^{4}$ Department of Paediatrics, The Chinese University of Hong Kong, Shatin, Hong Kong

\begin{abstract}
Background: Travelers' diarrhea is the most common travel-related malady. It affects millions of international travelers to developing countries annually and can significantly disrupt travel plans.
\end{abstract}

Objective: To provide an update on the evaluation, diagnosis, treatment, and prevention of traveler's diarrhea.

Methods: A PubMed search was completed in Clinical Queries using the key term "traveler's diarrhea". The search strategy included meta-analyses, randomized controlled trials, clinical trials, observational studies, and reviews. The search was restricted to English literature. Patents were searched using the key term "traveler's diarrhea" from www.freepatentsonline.com.

\section{A R T I C L E H I S T O R Y}

Received: November 22, 2018 Revised: April 30, 2019 Accepted: May 10, 2019

DOI: $10.2174 / 1872213 \times 13666190514105054$

CrossMark
Results: Between $10 \%$ and $40 \%$ of travelers develop diarrhea. The attack rate is highest for travelers from a developed country who visit a developing country. Children are at particular risk. Travelers' diarrhea is usually acquired through ingestion of food and water contaminated by feces. Most cases are due to a bacterial pathogen, commonly, Escherichia coli, and occur within the first few days after arrival in a foreign country. Dehydration is the most common complication. Pretravel education on hygiene and on the safe selection of food items is important in minimizing episodes. For mild travelers' diarrhea, the use of antibiotic is not recommended. The use of bismuth subsalicylate or loperamide may be considered. For moderate travelers' diarrhea, antibiotics such as fluoroquinolones, azithromycin, and rifaximin may be used. Loperamide may be considered as monotherapy or adjunctive therapy. For severe travelers' diarrhea, antibiotics such as azithromycin, fluoroquinolones, and rifaximin should be used. Azithromycin can be used even for the treatment of dysentery whereas fluoroquinolones and rifaximin cannot be used for such purpose. Recent patents related to the management of travelers' diarrhea are discussed.

Conclusion: Although travelers' diarrhea is usually self-limited, many travelers prefer expedient relief of diarrhea, especially when they are traveling for extended periods by air or ground. Judicious use of an antimotility agent and antimicrobial therapy reduces the duration and severity of diarrhea.

Keywords: Antibiotic, antimotility agent, contaminated food, Escherichia coli, oral rehydration, vaccination.

\section{INTRODUCTION}

Travelers' diarrhea is generally defined as the passage of $\geq 3$ unformed stools per 24 hours plus at least one additional symptom (such as nausea, vomiting, abdominal cramps, fever, blood/mucus in the stools, or fecal urgency) that develop while abroad or within 10 days of returning from any resource-limited destinations [1-3]. In the pediatric age group,

\footnotetext{
*Address correspondence to this author at the University of Calgary, A1berta Children's Hospital, \#200, $233-16^{\text {th }}$ Avenue NW, Calgary, Alberta, Canada T2M 0H5; Tel: (403) 230 3300; Fax: (403) 230 3322;

E-mail: aleung@ucalgary.ca
}

travelers' diarrhea is defined as a $\geq 2$-fold increase in the frequency of unformed stools rather than $\geq 3$ unformed stools per 24 hours, with other aforementioned conditions applied [1, 4]. Travelers' diarrhea is the most common travel-related malady. It affects millions of individuals traveling to developing countries annually and can disrupt travel plans, ruining a holiday not only for the patient but for the entire family. During prolonged ground or air transportation, diarrhea may incapacitate the traveler [5]. Anticipatory guidance on prudent food and beverages selection and preparation, observance of personal hygiene, pretravel vaccination with appropriate enteric vaccines if indicated, and judicious use of antimicrobial and antimotility agents can reduce the 
incidence and severity of travelers' diarrhea. Due to the popularity of international travels, the incidence of travelers' diarrhea is increasing [1]. Clinicians have to be knowledgeable in the recognition and management of this condition. This paper provides an update on the epidemiology, etiology, clinical manifestations, complications, diagnosis, management, and prevention of travelers' diarrhea. Recent patents related to the management of travelers' diarrhea are also discussed.

\section{METHODS}

A PubMed search was completed in Clinical Queries using the key term "traveler's diarrhea". The search strategy included meta-analyses, randomized controlled trials, clinical trials, observational studies, and reviews. The search was restricted to English literature. Patents were searched using the key term "traveler's diarrhea" from www.freepatentsonline.com.

\section{DEFINITIONS}

The expert panel of the International Society of Travel Medicine uses the following functional impact to define the severity of travelers' diarrhea [6].

Mild (acute) diarrhea is tolerable, not distressing, and does not interfere with planned activities. Moderate (acute) diarrhea is distressing or interferes with planned activities. Severe (acute) diarrhea is incapacitating or completely prevents planned activities. All dysentery (passage of grossly bloody stools) is considered severe.

The expert panel defines persistent diarrhea as diarrhea that lasts for $\geq 14$ days [6]. Conventionally, chronic diarrhea is defined as diarrhea that lasts for $\geq 1$ month [4].

\section{EPIDEMIOLOGY}

Overall, travelers' diarrhea affects 10 to $40 \%$ of travelers $[1,2,7,8]$. The incidence varies according to the traveler's destination of travel and country of origin, the duration of exposure, and the season of travel $[1,2,7,8]$. The sex ratio is approximately equal $[9,10]$. There is a genetic predisposition to the development of travelers' diarrhea [11]. More than one episode of diarrhea might develop within a single trip.

The incidence is highest in destinations where hygienic practices and sanitation are poor, particularly in those regions with warmer climates [2, 9]. High-risk destinations (incidence rate of travelers' diarrhea $\geq 20 \%$ ) include Africa (with the exception of South Africa), South and Central America, South and Southeast Asia, Mexico, Haiti, and the Dominican Republic [2, 12]. Intermediate-risk destinations (incidence rate of travelers' diarrhea 8 to $<20 \%$ ) include Southern and Eastern Europe, Central and East Asia (including China and Russia), the Middle East (including Israel), South Africa, and Caribbean Islands [2]. Low-risk destinations (incidence rate of travelers' diarrhea $<8 \%$ ) include North America, Northern and Western Europe, Australia, New Zealand, Singapore, and Japan. The risk of acquiring travelers' diarrhea is highest for travelers from a developed country who visit a developing country $[2,4,5,13]$. In contrast, the risk is lower for travelers from a developing coun- try who visit another developing country, possibly because of previous exposure and subsequent immunity to the offending pathogens [4]. The incidence is lower in winter months and higher in summer months in the same tourist destinations $[2,3,9,14]$.

Travelers' diarrhea is usually acquired by the fecal-oral transmission of the causative pathogen, typically through ingestion of food or water contaminated by feces. Occasionally, travelers' diarrhea may be acquired by handling contaminated objects or from accidental swallowing of contaminated water from swimming pools and other recreational water sources [5]. Insects particularly flies are important vectors for some foodborne enteric pathogens.

Children, especially the young ones, are at higher risk because of their natural curiosity and propensity to indiscriminately touch multiple objects and to put objects into their mouths. Furthermore, they are less selective in the type and source of food they consume, less likely to receive pretravel medical advice, and less likely to constantly adhere to the recommended hygiene measures $[1,4,7]$.

Other risk factors include gastric hypochlorhydria, use of antacids (especially proton pump inhibitors), pre-existing medical conditions (e.g., inflammatory bowel disease, diabetes mellitus, chronic renal failure, immunodeficiency) and adventurous eating habits [3-5, 9, 15]. Generally, campers and backpackers are also at higher risk than those who stay in hotels, possibly reflecting different standards of hygiene $[3,9]$.

\section{ETIOLOGY}

Generally, pathogens can be identified in approximately $85 \%$ of cases [4]. Bacteria account for up to $90 \%$ of identified pathogens for travelers' diarrhea [16]. Escherichia coli, especially Enterotoxigenic E. coli (ETEC), is the most common pathogen worldwide. ETEC is responsible for 30 to $60 \%$ of all cases of travelers' diarrhea and is a significant cause of childhood morbidity and mortality in the developing world, especially in Africa and Lain America [1]. Other bacterial pathogens include Enteroaggregative E. coli (EAEC), Enteroinvasive E. coli (EIEC), Diffusely Adherent E. coli (DAEC), Salmonella spp, Shigella spp, Campylobacter spp, and Yersinia enterocolitica [2, 4, 17-19]. Less common bacterial pathogens include Plesiomonas shigelloides, Aeromonas hydrophilia, Bacteroides fragilis, Arcobacter spp, Clostridium difficile, Vibrio cholerae, and Vibrio parahaemolyticus [7, 20-22]. Travelers taking medications for prophylaxis of malaria or antibiotics might develop diarrhea due to Clostridium difficile [2]. Infection with Vibrio species is often associated with ingestion of partially cooked or raw seafood [4].

Viral pathogens such as norovirus, rotavirus, astrovirus, and enteric adenovirus may be responsible for up to $10 \%$ of cases of travelers'diarrhea [17, 21, 23, 24].

Protozoal parasites such as Giardia lamblia (also known as Giardia intestinalis), Entamoeba histolytica, Cyclospora cayetanensis, Dientamoeba fragilis, Cystoisospora belli (also known as Isospora belli), Cryptosporidium parvum, and Microsporidium spp are less common causes; however, they are increasing in importance when the diarrhea lasts for 
$\geq$ two weeks $[2,4,7,25,26]$. Recently, Yoshikawa et al. identified Ancylostoma ceylanicum as a novel etiological agent for travelers' diarrhea [27]. The authors reported four Japanese patients who visited Southeast Asia and Papua Guinea and developed travelers' diarrhea secondary to Ancylostoma ceylanicum infection.

\section{PATHOPHYSIOLOGY}

Travelers' diarrhea may be caused by increased secretion and/or decreased absorption of fluid and electrolytes across the intestinal epithelium. Pathogens that can lead to secretory diarrhea include, ETEC, Vibrio cholera and rotavirus $[9,23$, 28]. Infection by these pathogens leads to the secretion of neurotransmitters (e.g., 5-hydroxytryptamine) from enteroendocrine cells and activation of afferent neurons that stimulate submucosal secretomotor neurons resulting in an outpouring of electrolytes and fluid into the intestinal lumen [8]. Activation of adenylate cyclase and elevation of intracellular cAMP in the enterocytes mediated by the bacterial toxins may account for the pathogenesis of secretory diarrhea [29]. The majority of cholera is caused by the cholera toxinproducing $V$. cholerae strains of 01 and 0139 serogroups [29, 30]. ETEC can produce a heat-labile enterotoxin (LT), a heat-stable enterotoxin (ST), or both enterotoxins (LT/ST) $[21,31]$. Approximately two-thirds of ETEC produce LT, which is functionally and structurally similar to cholera toxin. The enterotoxins produced by ETEC are responsible for ETEC's virulence [31]. Other virulence factors include adhesion properties and colonization factors [31].

Impaired absorption of fluid and electrolytes with resultant diarrhea may result from the direct invasion of the intestinal mucosa or the destruction of enterocytes by the cytolytic toxins released by the pathogens [15]. Examples of these pathogens include Salmonella spp, Shigella spp, Campylobacter spp, Yersinia enterocolitica, and ETEC [32, 33].

\section{CLINICAL MANIFESTATIONS}

The majority of the diarrheal episodes develop during the first few days of exposure after arrival in a foreign country, with $>90 \%$ of the diarrheal episodes developing within the first two weeks of exposure [25]. The majority of bacterial and viral causative pathogens have an incubation period of $<24$ hours. The incubation period for Campylobacter jejuni is longer at 3 to 10 days [4]. On the other hand, the incubation periods of Giardia lamblia and Entamoeba histolytica are 3 to 25 days and 2 to 4 weeks, respectively [4].

The diarrhea is watery in approximately $86 \%$ of cases; however, it can also be loose, mucousy or bloody [1, 34]. Approximately $3 \%$ of patients have $\geq 10$ unformed stools per 24 hours [7, 34]. Most patients have 3 to 5 unformed stools per 24 hours [34]. Other symptoms include fecal urgency in 90 to $100 \%$, tenesmus in 71 to $80 \%$, colicky abdominal pain/abdominal discomfort in 40 to $77 \%$, nausea in 10 to $70 \%$, malaise in 50 to $58 \%$, fever in 10 to $30 \%$, vomiting in 5 to $20 \%$, mucoid stools in 3 to $10 \%$, and bloody stools in 2 to $10 \%$ of cases $[4,34]$. Symptoms vary according to the causative pathogen. Characteristically, ETEC present mainly with watery diarrhea without bloody stools or fever [4]. Yersinia enterocolitica, C. jejuni, and Shigella dysenteriae, on the other hand, often cause dysentery-like diarrhea, with bloody stools, fever, fecal urgency, and abdominal cramps $[4,25]$. Vomiting is characteristic of Norwalk virus and Rotavirus infection [23]. Profuse watery diarrhea is characteristically seen in Vibrio cholerae, Cyclospora cayetanensis, and Cryptosporidium parvum infection [34]. Upper gastrointestinal symptoms such as nausea, bloating, belching, vomiting, and abdominal pain are typically seen in patients with giardiasis $[25,34]$.

\section{DIAGNOSIS AND LABORATORY INVESTIGA- TIONS}

The diagnosis is mainly clinical based on the history of passage of $\geq 3$ unformed stools per 24 hours, plus at least one additional symptom (such as nausea, vomiting, abdominal cramps, fever, blood/mucus in the stools, or fecal urgency) that develops while abroad or within 10 days of returning from travel to a resource-limited setting [1, 3, 34]. Laboratory evaluation is generally unnecessary unless the patient appears toxic, has a high fever, is hospitalized, develops bloody, mucoid, or cholera-like diarrhea has severe abdominal cramps, is immunocompromised, has a significant underlying medical condition, or has persistent diarrhea not responding to empiric therapy $[6,7,15]$. If that is the case, a fresh stool sample should be sent for culture. Freshly passed stool samples should be collected on three different days and sent for microscopic examination for ova, cysts, and parasites. The likelihood that protozoal pathogens such as Giardia lamblia, Entamoeba histolytica, or Cryptosporidium parvum rather than a bacterium will be isolated from a stool specimen increases with the duration of diarrhea [6]. An assay for $C$. difficile toxin should be ordered if the patient has a history of antimicrobial therapy within the month preceding the onset of diarrhea. A real-time multiplex Polymerase Chain Reaction (PCR) has been developed for rapid identification of a broad array of pathogens in a single assay to define the cause of travelers' diarrhea with high sensitivity and specificity [7, 21, 35, 36]. However, multiplex PCR testing is expensive and not widely available. In addition, multiplex PCR testing cannot distinguish between viable and nonviable pathogens, may detect microorganisms that may not be the cause of diarrhea, and does not provide antibacterial susceptibility [36-38]. As such, good clinical judgement must be exercised. The use of multiplex PCR should be considered for patients hospitalized with travelers' diarrhea when rapid results are desirable and those with persistent diarrhea when non-molecular tests have failed to establish a diagnosis $[6,21]$.

\section{COMPLICATIONS}

Dehydration with or without electrolyte imbalance is the most common complication, particularly in children. Inappropriate rehydration solutions (excessively high glucose content or excessively low electrolyte content) might compound the problem $[39,40]$. Other less common complications include sepsis, hemolytic-uremic syndrome, postinfectious irritable bowel syndrome, $C$. difficile colitis (after antibiotic use), Guillain-Barré syndrome (after infection with $C$. jejuni), reactive arthritis (often associated with HLA-B27), acute myocarditis (rarely after infection with $C$. jejuni), and permanent short-term memory loss (after shellfish poisoning) [41-48]. Travelers' diarrhea can disrupt business trips 
and holidays. The financial loss and economic burden associated with travelers' diarrhea can be considerable.

\section{MANAGEMENT}

The goals of management are to maintain optimal hydration, minimize the severity and duration of diarrheal illness, prevent cancellation of planned activities, restore functional status, and eradicate the offending pathogen. Individuals at the extremes of age are particularly susceptible to and less tolerant of fluid and electrolyte loss. For most cases of travelers' diarrhea, correction of water and electrolyte loss is the mainstay of treatment and this can be accomplished preferably with properly designed oral rehydration solutions that can facilitate glucose and sodium cotransport across the intestinal membrane $[5,39,49,50]$. Prepackaged oral rehydration salt should be mixed with clean, boiled, bottled, or filtered water [39]. Breastfeeding should be encouraged in infants who are breastfed [51]. These infants should be supplemented with an oral rehydration solution if necessary [51].

Although antisecretory/antimotility agents do not eradicate the pathogen, they can shorten the duration and reduce the severity of diarrhea. Antisecretory/antimotility agents should be considered for travelers who prefer expedient relief of diarrhea. This is especially so when they have to travel for extended periods by air or ground. The short-term use of loperamide (Imodium) has been approved for the treatment of individuals $\geq 2$ years of age with travelers' diarrhea [52]. Loperamide is an opioid-like agent that is taken orally [53]. The medication is relatively nonabsorbable; hence only insignificant amounts reaches the systemic circulation. It has a potent antisecretory effect in addition to its antimotility activity [53]. The drug has a rapid onset of action [54]. It is particularly useful in the management of mild and moderate travelers' diarrhea [53]. The recommended loading dose for individuals $\geq 12$ years is $4 \mathrm{mg}$, followed by $2 \mathrm{mg}$ per episode of diarrhea (maximum $16 \mathrm{mg}$ per day) [53]. For children 6 to 11 years, the recommended loading dose is $2 \mathrm{mg}$, followed by $1 \mathrm{mg}$ per episode of diarrhea (maximum $6 \mathrm{mg}$ per day) and that for children 2 to 5 years old, the recommended loading dose is $1 \mathrm{mg}$, followed by $1 \mathrm{mg}$ per episode of diarrhea (maximum $3 \mathrm{mg}$ per day). Loperamide has a favorable safety profile but should be avoided if the patient has a high fever, severe abdominal cramps, or dysentery because of the risk of toxic megacolon and intestinal perforation $[1,25]$. The medication should not be given to children $\leq 2$ years of age because of the potential risk of central nervous system depression $[1,7]$. Two systematic reviews including 28 studies concluded that adding loperamide to antibiotic therapy may hasten resolution of travelers' diarrhea with no or minimal side effects compared to antibiotic therapy alone [55]. Diphenoxylate (Lomotil), an antimotility agent, is also effective for the treatment of travelers' diarrhea by reducing the rate of stool frequency [34]. It is a centrally active opioid drug of the phenylpiperidine series that is used in combination with a subtherapeutic dose of atropine for the treatment of diarrhea. The recommended dose for individuals $\geq 13$ years is $5 \mathrm{mg}$ of diphenoxylate $/ 0.5 \mathrm{mg}$ of atropine every 6 hours for a maximum of 48 hours. The safety and effectiveness of diphenoxylate have not been established in children $<12$ years of age. Bismuth subsalicylate (Pepto Bismol) is also effective for the treatment of travelers' diarrhea [56]. The medication possesses antisecretory properties and is capable of neutralizing the toxins of ETEC [11]. The recommended dose for individuals $\geq 12$ years is four tablets (262 $\mathrm{mg} /$ tablet) or $60 \mathrm{ml}$ (regular strength) every 30 to 60 minutes until diarrhea subsides or eight doses have been taken [34]. The recommended dose for children 10 to 11 years, 6 to 9 years, and 3 to 5 years is 1 tablet or $15 \mathrm{ml}, 2 / 3$ tablet or $10 \mathrm{ml}$, and $1 / 3$ tablet or $5 \mathrm{ml}$, respectively. The medication, however, is less effective than loperamide $[25,56]$. Other disadvantages include the large and frequent doses of the liquid preparation of medication needed and the potential for adverse events such as blackening of the tongue, black stools, salicylate toxicity, Reye's syndrome, and tinnitus. This drug is not recommended for pregnant women and children [56]. For those patients with coexisting severe nausea and vomiting, ondansetron (Zofran) may be given [49, 5759].

Antimicrobial therapy is effective in reducing the duration and severity of traveler's diarrhea [52,60]. For travelers going to moderate and high-risk areas, it might be appropriate to provide them with a short course of a suitable antibiotic with the advice to start antimicrobial treatment should they develop moderate or severe diarrhea [25]. The choice of the antibiotic should be guided by resistance surveillance data as well as careful assessment of the benefits and risks associated with its use to both the patient and society [61]. Differences in effectiveness of antimicrobials between regions are likely due to the local pattern of antimicrobial resistance [56]. Fluoroquinolones, such as ciprofloxacin (Cipro), levofloxacin (Levaquin, Leva-Pak, Quixin), and ofloxacin (Floxin), are efficacious against a broad spectrum of bacterial enteric pathogens. The recommended dose of ciprofloxacin for adults is $750 \mathrm{mg}$ as a single dose (children, 20 to $30 \mathrm{mg} / \mathrm{kg} /$ day in 1 or 2 divided doses) or $500 \mathrm{mg}$ daily for 3 days, that of levofloxacin is $500 \mathrm{mg}$ as a single dose (children, 10 to $20 \mathrm{mg} / \mathrm{kg} /$ day in 1 or 2 divided doses) or for 3 days, and that of ofloxacin is $400 \mathrm{mg}$ as a single dose or for 3 days [6]. The safety and efficacy of ofloxacin have not been established in children $<12$ years of age. Fluoroquinolones are drugs of choice for most destinations [7]. Resistance to fluoroquinolones is increasing, particularly in Southeast Asia where Campylobacter jejuni is a common cause of travelers' diarrhea. Fluoroquinolones are contraindicated in pregnant women and are not recommended for children under 8 years of age [18]. Azithromycin (Zithromax, Azithrocin) and fluoroquinolones have similar efficacy [18]. The recommended dose of azithromycin is $500 \mathrm{mg}$ (children, $10 \mathrm{mg} / \mathrm{kg} /$ day, maximum $500 \mathrm{mg}$ ) daily for three days or $1000 \mathrm{mg}$ as a single dose. The single dose regimen may have to be repeated if symptoms persist for up to three days $[1,6$, 18, 34]. Azithromycin is highly effective against most pathogens that cause travelers' diarrhea and is effective in the treatment of patients with Campylobacter infection that is resistant to fluoroquinolones. It is the drug of choice for treatment of severe or febrile travelers' diarrhea, dysentery, and moderate to severe travelers' diarrhea among travelers to Southeast Asia where fluoroquinolone-resistant pathogens are prevalent $[6,7,18,34]$. The medication is safe to use in pregnant women and children. Rifaximin (Xifaxan, Xifaxante, Normix) is a nonabsorbable ( $<0.4 \%$ absorbed $)$, locally 
active antimicrobial that can achieve high concentrations in the intestines [62, 63]. The medication binds to the beta subunit of the bacterial RNA polymerase and inhibits bacterial RNA synthesis. Rifaximin has a broad spectrum of activity and has been approved for the treatment of individuals $\geq$ 12 years of age who present with uncomplicated travelers' diarrhea [4, 64]. The recommended dose of rifaximin is $200 \mathrm{mg}$ three times a day for three days $[6,34]$. The medication is poorly absorbed from the gastrointestinal tract, thereby achieving high concentration in the intestines [48]. The medication has minimal side effects [63]. Rifaximin is less effective for the treatment of invasive pathogens and should not be used for the treatment of dysentery [6].

The expert panel of the International Society of Travel Medicine has made the following recommendations for the treatment of travelers' diarrhea depending on its severity in addition to the conservative treatment such as fluid and electrolyte replenishment [6]:

For mild travelers' diarrhea, the use of antibiotic is not recommended (strong recommendation, moderate level of evidence). The use of bismuth subsalicylate or loperamide may be considered (strong recommendation, moderate level of evidence) [6].

For moderate travelers' diarrhea, antibiotics such as fluoroquinolones (strong recommendation, moderate level of evidence), azithromycin (strong recommendation, high level of evidence), and rifaximin (weak recommendation, moderate level of evidence) may be used [6]. Loperamide may be considered as monotherapy (strong recommendation, high level of evidence) for the treatment of moderate travelers' diarrhea and adjunctive therapy (strong recommendation, high level of evidence) for the treatment of moderate to severe travelers' diarrhea [6].

For severe travelers' diarrhea, antibiotics such as azithromycin (strong recommendation, moderate level of evidence), fluoroquinolones (weak recommendation, moderate level of evidence), and rifaximin (weak recommendation, moderate level of evidence) should be used [6]. In this regard, azithromycin can be used even for the treatment of dysentery whereas fluoroquinolones and rifaximin cannot be used for such purpose [6].

The majority of cases of travelers' diarrhea are mild and self-limited. Most cases do not require treatment with antibiotics or antimotility/antisecretory agents. Medical attention should be sought if there are symptoms/signs of dehydration, bloody diarrhea, intractable vomiting, severe abdominal pain, and high fever, especially in those who did not improve with empiric antibiotic therapy within 36 hours [5, 34].

\section{ADJUNCTIVE THERAPIES}

Probiotics such as Lactobacillus rhamnosus GG, Lactobacillus acidophilus, and Saccharomyces boulardii have been used in the treatment as well as the prevention of travelers' diarrhea because of their beneficial effects on intestinal flora and resultant suppression of pathogenic bacteria $[65,66]$. A 2018 meta-analysis of 12 randomized clinical trials with a total of 16 intervention arms $(n=3,736)$ showed a significant reduction in travellers' diarrhea with $S$. boulardii prophylaxis (risk ratio: $0.79 ; 95 \%$ confidence interval:
0.72 to $0.87 ; \mathrm{p}<0.001)$ [67]. There was a trend of reduction in travelers' diarrhea with $L$. rhamnosus $G G$ prophylaxis (p $=0.008$ ) while there was no reduction in travelers' diarrhea with $L$. acidophilus prophylaxis. It has been suggested that the second generation of bifidobacterial-galactooligosaccharides prebiotic has the potential in the prevention of travelers' diarrhea [68]. The prebiotic, however, has not been subjected to rigorous clinical trials [69]. Further studies will be needed to determine if prebiotics and probiotics could be used in the prevention of travelers' diarrhea.

\section{PROPHYLAXIS}

The majority of diarrheal diseases can be prevented by implementing Water, Sanitation, and Hygiene (WASH) programs aiming at interrupting fecal-oral route of transmission [70]. Travelers to high-risk areas should be counseled on self-diagnosis and treatment of travelers' diarrhea. They should also be counseled on personal hygiene and on prudent food and beverages selection and preparation. Frequent handwashing with soap/alcohol-based detergents/hand sanitizer and with the cleanest water available, especially after defecation and urination and before preparing or eating food, is of utmost importance. The rule "cook it, boil it, peel it, or forget it" is logical but is difficult to closely follow [9]. High-risk products that can be easily contaminated should be avoided. These items include cream-filled desserts, cold sauces and dressings, salads, raw and leafy vegetables that are difficult to clean, fruits that are difficult to peel, undercooked/raw meat and seafood, cooked food that has been left at room temperature for several hours, food brought from street vendors, unpasteurized dairy products, ice cubes and tap water [5]. Buffet foods and reheated prepared foods are associated with a higher risk of contamination. Fresh and thoroughly cooked meats and vegetables that are still hot, fruit juice or carbonated soft drinks with intact seals, fruits that are peeled by the traveler just prior to eating, pasteurized dairy products, bottled or canned water, hot tea, and hot coffee are usually safe. Food should be well cooked with the interior of the cooked food measuring $\geq 70^{\circ} \mathrm{C}$ to kill the pathogens [9]. Travelers should be advised to avoid shellfish from water that is contaminated as marine toxins cannot be killed by cooking. Boiled beverages should be served at $\geq 60^{\circ} \mathrm{C}$ [7]. Contact with potentially contaminated recreational waters should be avoided [5].

Chemoprophylaxis should not be routinely used because of the potential of the alteration of gut flora, development of adverse events, development of antimicrobial resistance, possible drug interactions, the expense of the medication, a false sense of security, and confusion as to how to treat those with diarrhea in spite of chemoprophylaxis [2]. Antimicrobial prophylaxis should be considered for individuals who cannot afford to become sick, such as politicians or elite athletes. It should also be considered for those individuals who have greater susceptibility to travelers' diarrhea and who are at high risk of severe complications, such as those who are very old, are immunocompromised, are prone to complications (e.g., dehydration) from diarrhea, or have a chronic illness (e.g., inflammatory bowel disease, short bowel syndrome, gastric hypochlorhydria, congestive heart failure, diabetes mellitus, chronic renal failure) [6, 25]. Chemoprophylaxis, if necessary, should be short-term. It should not 
exceed 14 days [71]. Rifaximin is effective and safe. It is the drug of choice for the prevention of travelers' diarrhea [2, 6 , $48,71]$. A meta-analysis of five randomized controlled trials $(\mathrm{n}=879)$ comparing rifaximin with placebo found significant reduction in risk of travelers' diarrhea with rifaximin (pooled risk ratio: $0.478 ; 95 \%$ confidence interval: 0.375 to $0.610 ; \mathrm{p}<0.001)$, especially in individuals who are at risk for travelers' diarrhea [72]. If rifaximin is used for prophylaxis, azithromycin should be used to treat break-through travelers' diarrhea. Since azithromycin is effective in the treatment of travelers' diarrhea, including invasive forms of travelers' diarrhea, it is recommended that azithromycin should not be used for prophylaxis [62]. The use of fluoroquinolones for prophylaxis of travelers' diarrhea is not recommended either because of increasing bacterial resistance and adverse effects associated with prolonged use of fluoroquinolones [6].

Bismuth subsalicylate may also be considered for the prevention of travelers' diarrhea [6]. The medication provides a protective rate of 60 to $65 \%$ against travelers' diarrhea [6]. The dosing schedule (2.1 to $4.2 \mathrm{~g}$ per day divided into 4 divided doses to be given with meals and at bedtime) is inconvenient for the traveler because of the large quantities of medication that have to be taken four times a day [2, 71]. Also, bismuth subsalicylate has an unpleasant taste, turns the tongue and stool black, and has the potential for salicylate toxicity and encephalopathy $[2,52]$. The medication is not recommended for children or for individuals with aspirin allergy, renal insufficiency, or gout, or for those who are taking anticoagulants, probenecid, or methotrexate.

WC-rBSCT (Dukoral) vaccine is an oral, killed wholecell cholera vaccine that consists of $V$. cholerae 01 organisms and the nontoxic, B subunit of cholera toxin [73]. The vaccine has overall efficacy of $85 \%$ against challenge with $V$. cholerae $\mathrm{O} 1$ but not effective against 0139 serogroups [4, 73]. The antigenic similarity between nontoxic, B subunit of cholera toxin and LT of ETEC allows protection against diarrhea caused by LT-ETEC and LT/ST-ETEC $[2,4]$. The vaccine, primarily designed for the prevention of cholera, has been recommended by some investigators for the prevention of travelers' diarrhea in people visiting endemic areas $[74,75]$. The vaccine has been proven to be safe and well tolerated [73]. Two doses of the Dukoral vaccine are recommended and they should be given at least seven days apart on an empty stomach. Based on randomized controlled trials, a Cochrane review, however, found that there is no significant difference in efficacy between Dukoral vaccine and placebo in the prevention of travelers' diarrhea [74]. Although there is insufficient evidence to support the routine use of Dukoral vaccine for the prevention of travelers' diarrhea caused by ETEC [52], some investigators suggest that Dukoral vaccine should be considered for travelers $\geq 2$ years of age who will be visiting areas where there are high risk of contracting travelers' diarrhea caused by ETEC. The vaccine may also benefit those individuals who are at high risk of severe complications, such as those who are immunocompromised, are prone to complications from diarrhea, or have a chronic illness $[52,76]$.

Vaxchora, a live attenuated, single dose, oral cholera vaccine, is the only vaccine approved by the Food and Drug
Administration (FDA) for the prevention of cholera [70, 77]. Cholera is caused by $V$. cholerae serogroup 01 , which is responsible for the majority of outbreaks $(>99 \%$ of global cases) $[70,77]$. The vaccine is recommended for adults 18 to 64 years of age traveling to areas where cholera is epidemic or endemic and should be considered for those who are at high risk of exposure $[2,77,78]$. Vaxchora is well tolerated with no significant adverse events [79]. The vaccine, however, has not been shown to be effective against serogroup 0139 or other non-01 serogroups [78]. Shanchol is an oral vaccine containing killed $V$. cholerae 01 and 0139 organisms [80]. The vaccine has been found to be immunogenic, effective, and safe [81]. Two doses of the Shanchol vaccine are recommended and they should be given at least 14 days apart [80]. The vaccine was subjected to a large-scale field trial in Kolkata in India where cholera was endemic [82]. It was found that 69 of 31,932 vaccine recipients and 219 of 34,968 controls developed cholera during a 5-year follow-up. The cumulative protective efficacy of the Shanchol vaccine at 5 years was 65\% (95\% confidence interval: 52 to $74 ; \mathrm{p}<$ $0.0001)$ [82]. Euvichol is another oral vaccine containing killed $V$. cholerae 01 and 0139 organisms [83]. The vaccine still has an efficacy of $65 \%$ after 5 years for those children $>$ 5 years of age [83].

Typhoid fever is caused by Salmonella enterica serotype Typhi [84]. Typhoid vaccine is recommended for travelers to areas with poor sanitation and hygiene. Two typhoid vaccines are globally available, namely, a parenteral inactivated Vi Capsular Polysaccharide vaccine (ViCPS) and an oral live-attenuated vaccine, Ty21a [84]. Only a single dose of the inactivated vaccine (ViCPS) given intramuscularly is required and should be administered $\geq 2$ weeks prior to travel [10]. On the other hand, 4 doses of the oral vaccine (Ty21a) are required and should be administered two days apart, with the last dose given $\geq 1$ week prior to travel [10]. The oral vaccine has to be refrigerated and taken on an empty stomach with a glass of cool water [10]. Both vaccines provide approximately $75 \%$ protection that lasts for 2 to 3 years [84]. The ViCPS vaccine is licensed for use for individuals $\geq 2$ years whereas the Ty21a for individuals $\geq 5$ years $[10,84]$. Antibiotics and antimalarials, if taken concurrently, may inhibit the oral typhoid vaccine because these agents may prevent a sufficient immune response from the oral vaccine [10]. The WHO recommends that oral typhoid vaccine should be given at least one week before or after the ingestion of antibiotics and antimalarials. The newly available Tybar-TCV is a typhoid conjugate vaccine which contains Vi capsular polysaccharide of Salmonella enterica serovar typhi Ty2 conjugated to a tetanus toxoid carrier protein. One single dose of Tybar-TCV injected intramuscularly is necessary and should be administered $\geq 2$ weeks prior to travel. The vaccine has been proven to be safe, well tolerated, and efficacious. Recently, the WHO has recommended Tybar-TCV as the preferred vaccine for the prevention of typhoid fever [85].

Rotavirus is the most common cause of gastroenteritis in children [23]. Clinical trials showed that three doses of a live pentavalent (G1, G2, G3, G4, and P1), human-bovine reassortant vaccine, $\left(\right.$ RotaTeq $\left.^{\circledR}\right)$ and two doses of a monovalent human-attenuated rotavirus vaccine RIX4414 $\left(\right.$ Rotarix $\left.^{\circledR}\right)$ are highly effective in the prevention of severe rotavirus diarrhea 
and its associated mortality and morbidity [86, 87]. More recently, an oral human-bovine natural reassortant vaccine (116E) (Rotavac) produced in India has also been shown to be effective [88]. Bhandari et al. randomly assigned 4532 and 2267 children $\leq 2$ years of age to receive three doses of Rotavac vaccine and placebo, respectively [88]. The authors found that the efficacy of Rotavac vaccine against severe gastroenteritis in these children was $55.1 \%$ (95\% confidence interval: 39.9 to $66.4 ; \mathrm{p}<0.001)$. Co-infections may lead to an approximately $11 \%$ decrease in vaccine efficacy [89].

\section{PROGNOSIS}

Travelers' diarrhea is usually self-limited. If left untreated, approximately $50 \%$ of the patients are spontaneously cured in 48 hours and, in the majority of patients, the average duration diarrhea is 4 to 5 days $[7,90]$. Approximately $5 \%$ and $1 \%$ of affected individuals have diarrhea that persists for longer than 14 days and 1 month, respectively [16, 25, 91]. Approximately $13 \%$ of patients are confined to bed for 1 to 2 days, and about $0.4 \%$ of patients require hospital admission while abroad or after returning home [7]. The clinical course tends to be more severe and prolonged in children, especially those younger than 2 years of age.

\section{CONCLUSION}

Travelers' diarrhea is the most common cause of disability among international travelers to developing countries. Travelers to the high-risk region should receive pretravel counseling on personal hygiene and anticipatory guidance on food safety and pretravel vaccination with enteric vaccines. They should exercise caution by careful selection of safer food. Judicious use of antimicrobial and antimotility agents can reduce the severity of travelers' diarrhea. Nevertheless, reduction in the incidence of travelers' diarrhea depends more on the level of sanitation at the destination site rather than the precautions and intervention implemented by the traveler [7].

\section{CURRENT \& FUTURE DEVELOPMENTS}

Currently, there are no vaccines licensed for the prevention of ETEC infection which is the principal cause of travelers' diarrhea [92, 93]. Research is urgently needed for the development of ETEC vaccines [93]. Colonization Factors (CF) and LT enterotoxin are antigens in the development of major ETEC candidate vaccines [31]. LT entertoxin exerts its toxic effect by binding to ganglioside $1\left(\mathrm{GM}_{1}\right)$ at the apical surface of intestinal cells [31]. $\mathrm{GM}_{1}$-binding LT is a strong immunogen and adjuvant and can serve as a carrier or platform for multivalent vaccine development against ETEC and other pathogens [94]. Huang et al. identified LT epitopes and demonstrated that substitution of LT epitopes eliminated LT enterotoxicity without altering $\mathrm{GM}_{1}$-binding [94]. ETEC vaccine development has been hindered by a lack of suitable animal models [95]. Travelers could serve as ideal candidates for clinical trials for the development of future vaccines.

Borde et al. developed a novel multivalent oral vaccine which contains killed ETEC over-expressing the main ETEC colonization factors and a recombinant enterotoxin B subunit protein given together with a recently developed intestinal- mucosal adjuvant double mutated LT [96]. The authors produced a dry-powder formulation by freeze-drying the vaccine using insulin as a stabilizer. Oral-intragastric immunization of mice with the vaccine elicited strong intestinal mucosal and serum antibody responses against all vaccine antigens.

It has been shown that $\mathrm{CFaE}$, a subunit of the Colonization Factor Antigen $1(\mathrm{CFA} / 1)$, is required for the adhesion of ETEC to intestinal cells of the host [92]. As such, human antibodies against $\mathrm{CFaE}$ by blocking colonization of ETEC may serve as immunoprophylactic agents for the prevention of ETEC-related diarrhea. Recently, Giuntini et al. identified a panel of anti-CFaE human monoclonal antibodies that are active against ETEC with high potency [92]. Oral administration of anti-CFaE human monoclonal antibodies in either $\mathrm{IgG}$ or secretary IgA form inhibited intestinal colonization in mice challenged with ETEC [92]. In the absence of an effective vaccine against ETEC infection, these anti-CFaE human monoclonal antibodies have the potential to be oral immunoprophylactic agents against ETEC infection.

Very recently, a live, heat-stable, oral Bovine Rotavirus Pentavalent Vaccine (BRV-PV) has been developed in India. A Phase III randomized controlled trial of the vaccine in 3508 infants in Niger showed an efficacy of $66.7 \%(95 \%$ confidence interval: 49.9 to 77.9$)$ against severe rotavirus gastroenteritis [97].

Current typhoid vaccine cannot be used in children $<2$ years of age due to poor immunogenicity [98]. Mitra et al. prepared a novel Vi-TT conjugate typhoid vaccine $\left(\right.$ PedaTyph ${ }^{\mathrm{TM}}$ ) by binding $\mathrm{Vi}$ to tetanus toxoid [98]. Two doses of the vaccine are required and should be given 6 weeks apart. Of the 1765 children aged 6 months to 12 years recruited into the study, 905 children received the vaccine intramuscularly and 860 children served as the control. The authors found that the vaccine was highly immunogenic and efficacious with minimal adverse events. GelSite-OAC ${ }^{\text {TM }}$ is a novel synthetic typhoid vaccine that is currently being developed [84]. The vaccine is based on the fact that Oacetylated high molecular weight polygalacturonic acid shares the same backbone as Vi polysaccharide of $S$. typhi [84]. Preliminary data showed that the vaccine is safe, highly immunogenic, and effective even in individuals under 2 years of age.

Racecadotril is an anti-secretory agent effective in the treatment of diarrhea. The drug, however, has not been studied in travelers who have diarrhea.

It has been shown that the ST produced by ETEC is poorly immunogenic and potently toxic [99]. Thus, ST itself cannot induce anti-ST immunity, nor could it be a safe antigen even if it were immunogenic. Therefore, there is an unmet need to produce a vaccine which can elicit an immune response and can also induce protective immunity to multiple CFA antigens, as well as anti-LT and anti-ST immunity that would be broadly protective against ETEC. Sack and Zhang disclosed polypeptides comprising up to 9 antigenic elements of ETEC virulence determinants: 7 CFA adhesins [CFA/I, CFA/II (CS1, CS2, CS3), CFA/IV (CS4, CS5, CS6)] and 2 enterotoxins (LT, ST) that were genetically fused together [99]. These polypeptides can be used in the develop- 
ment of vaccines effective in the prevention of travelers' diarrhea caused by ETEC.

Savkovic and Roy disclosed an invention for the prevention and/or treatment of enteropathogenic bacterial infection in the gastrointestinal tract by concurrently administering to the subject a low molecular weight polyethylene glycol in combination with other antibiotic and antidiarrheal agents [100]. According to the authors, the low molecular weight polyethylene glycol has a molecular weight between about 100 daltons and 5000 daltons. The authors claimed that the invention is effective in the prevention and/or treatment of enteropathogenic bacterial pathogens, such as ETEC, EIEC, Salmonella, and Shigella which are important causes of travelers' diarrhea.

Savarino disclosed a method for the induction of immunity and prevention of diarrhea resulting from Escherichia coli [101]. The method provides for the induction of B-cell mediated immunity and for the induction of antibody capable of inhibiting the adherence and colonization of Escherichia coli, to intestinal cells of the host, thereby travelers' diarrhea can be prevented. An immune response can be induced by administrating a priming dose of an immunogen comprising whole or an antigenic polypeptide fragment of Escherichia coli fimbriae or whole or antigenic polypeptide fragment of Escherichia coli fibrillae with unit dose ranging from $50 \mu \mathrm{g}$ to $1 \mathrm{mg}$ of the immunogen in a buffered aqueous solution. Booster doses should be administered at least 1 week after priming dose with a unit dose ranging from $50 \mu \mathrm{g}$ to $1 \mathrm{mg}$ of the immunogen in a buffered aqueous solution.

It is a well-known fact that different polymorphic forms of the same drug may have substantial differences in certain pharmaceutically important properties. Because amorphous solids do not have lattice energy, they usually dissolve in a solvent more rapidly and consequently may provide enhanced bioavailability characteristics such as a higher rate and extent of absorption of the compound from the gastrointestinal tract. Also, amorphous forms of a drug may offer significant advantages over crystalline forms of the same drug in the manufacturing process of solid dosage form such as compressibility. Consequently, it would be a significant contribution to the art to provide an amorphous form of rifaximin having increased solubility. Rao et al. disclosed an invention which can provide amorphous rifaximin in bulk form [102]. The amorphous rifaximin is substantially pure with polymorphic purity of $99 \%$ or more.

As rifaximin is sparingly soluble in water, a formulation chemist often finds it difficult to prepare a consistent formulation using the known polymorphic forms. Hence, there is a need to prepare rifaximin in a form which is suitable for formulation and has increased solubility and stability. Ghagare et al. disclosed a complex comprising rifaximin and a complexing agent, wherein the complexing agent is a polyvinyl pyrrolidone or a cyclodextrin [103]. The complex of this invention exhibits enhanced solubility and stability of rifaximin.

Driessen disclosed dietary supplements for the prevention or treatment of traveler's diarrhea [104]. The supplements comprise of approximately $1000 \mathrm{mg}$ green tea extract with at least $90 \%$ catechins, $4 \mathrm{~g}$ partially hydrolyzed guar gum, 100mg L-theanine, and $5 \mathrm{~g}$ non-sugar sweetener not containing a polyol.

Cheng disclosed an invention pertaining to the use of the calcium-sensing receptor-activating nutrients for the prevention and/or treatment of diarrheal diseases [105]. The antidiarrheal composition consists of an aqueous solution of calcium, potassium, magnesium, zinc, sodium, chloride, bicarbonate, tryptophan; and, optionally, one or more ingredients selected from vitamins; preservatives; flavorings; buffers; carbohydrates; and the conjugate acid and conjugate base of butyrate and acetic acid, respectively. The invention is formulated for oral administration. The author claimed that the invention is effective in the treatment of diarrhea caused by E. coli, Vibrio cholerae, Vibrio parahaemolyticus, Clostridium perfringens, Clostridium difficile, Staphylococcus aureus, Salmonella spp., parvovirus, rotavirus, adenovirus, calicivirus, astrovirus, Cryptosporidia, Giardia lamblia, and Entamoeba histolytica.

Lefevre et al disclosed an invention comprising lyophylized Saccharomyces boulardii as an active ingredient and as sole probiotic, optionally in association with a pharmaceutically acceptable vehicle, wherein the composition is in a closed vial. The first airtight compartment comprising lyophilized $S$. boulardii powder and a second compartment comprising a solution, can be brought in airtight communication with one another to yield a suspension of $S$. boulardii to be administered to an individual upon opening of the vial [106]. According to the authors, the invention is effective in the prevention or treatment of travelers' diarrhea.

\section{CONSENT FOR PUBLICATION}

Not applicable.

\section{FUNDING}

This work was not funded, there was no honorarium, grant, or other form of payment received by the authors.

\section{CONFLICT OF INTEREST}

Professor Alexander K.C. Leung, Dr. Amy A.M. Leung, Dr. Alex H.C. Wong, and Professor Kam L. Hon confirm that this article has no conflicts of interest.

\section{ACKNOWLEDGEMENTS}

Professor Alexander K.C. Leung is the principal author. Dr Amy A.M. Leung, Dr Alex H.C. Wong, and Professor Kam L. Hon are the co-authors who contributed and helped with the drafting of this manuscript.

\section{REFERENCES}

[1] Ashkenazi S, Schwartz E, O'Ryan M.Travelers' diarrhea in children: What have we learnt? Pediatr Infect Dis J 2016; 35(6): 698700 .

[http://dx.doi.org/10.1097/INF.0000000000001145] [PMID: 26986771]

[2] LaRocque R, Harris JB. Travelers' diarrhea: Microbiology, epidemiology, and prevention. Available at: https://www.uptodate. com/contents/travelers-diarrhea-microbiology-epidemiology-andprevention (Accessed on: October 30, 2018).

[3] Steffen R. Epidemiology of travellers' diarrhea. J Travel Med 2017; 24: S2-5. 
[http://dx.doi.org/10.1093/jtm/taw072] [PMID: 28520996]

[4] Leung AK, Robson WL, Davies HD. Traveler's diarrhea. Adv Ther 2006; 23(4): 519-27.

[http://dx.doi.org/10.1007/BF02850040] [PMID: 17050494]

[5] Leggat PA, Goldsmid JM. Travellers' diarrhoea: Health advice for travellers. Travel Med Infect Dis 2004; 2(1): 17-22. [http://dx.doi.org/10.1016/j.tmaid.2004.01.005] [PMID: 17291952]

[6] Riddle MS, Connor BA, Beeching NJ, DuPont HL, Hamer DH, Kozarsky $\mathrm{P}$, et al. Guidelines for the prevention and treatment of travelers' diarrhea: A graded expert panel report. J Travel Med 2017; 24: S57-74.

[http://dx.doi.org/10.1093/jtm/tax060] [PMID: 28521004]

[7] Steffen R, Hill DR, DuPont HL. Traveler's diarrhea: A clinical review. JAMA 2015; 313(1): 71-80.

[http://dx.doi.org/10.1001/jama.2014.17006] [PMID: 25562268]

[8] Stoney RJ, Han PV, Barnett ED, Wilson ME, Jentes ES, Benoit CM, et al. Travelers' diarrhea and other gastrointestinal symptoms among Boston-area international travelers. Am J Trop Med Hyg 2017; 96(6): 1388-93.

[http://dx.doi.org/10.4269/ajtmh.16-0447] [PMID: 28719282]

[9] Al-Abri SS, Beeching NJ, Nye FJ. Traveller's diarrhoea. Lancet Infect Dis 2005; 5(6): 349-60.

[http://dx.doi.org/10.1016/S1473-3099(05)70139-0] [PMID: 15919621]

[10] Moore KS. Travelers' diarrhea: Risk reduction and management. Nurse Pract 2015; 40(11): 1-5.

[http://dx.doi.org/10.1097/01.NPR.0000472252.51574.26] [PMID: 26474195]

[11] DuPont HL. Systematic review: The epidemiology and clinical features of travellers' diarrhoea. Aliment Pharmacol Ther 2009; 30(3): 187-96.

[http://dx.doi.org/10.1111/j.1365-2036.2009.04028.x] [PMID: 19392866]

[12] El-Bahnasawy M, Morsy TA. Beyond immunization: Travelers' infectious diseases. 1-Diarrhea. J Egypt Soc Parasitol 2015; 45(1): 29-42.

[http://dx.doi.org/10.12816/0010847] [PMID: 26012216]

[13] Greenwood Z, Black J, Weld L, O'Brien D, Leder K, Von Sonnenburg $\mathrm{F}$, et al. Gastrointestinal infection among international travelers globally.J Travel Med 2008; 15(4): 221-8.

[http://dx.doi.org/10.1111/j.1708-8305.2008.00203.x] [PMID: 18666921]

[14] Mattila L, Siitonen A, Kyrönseppä H, Simula I, Oksanen P, Stenvik $\mathrm{M}$, et al. Seasonal variation in etiology of travelers' diarrhea. J Infect Dis 1992; 165(2): 385-8.

[http://dx.doi.org/10.1093/infdis/165.2.385] [PMID: 1730905]

[15] Dunn N, Gossman WG. TravelersDiarrhea.Available at: https://www.ncbi.nlm.nih.gov/books/NBK459348/ (Accessed on: September 18, 2018).

[16] Duplessis CA, Gutierrez RL, Porter CK. Review: Chronic and persistent diarrhea with a focus in the returning traveler. Trop Dis Travel Med Vaccines 2017; $3: 9$.

[http://dx.doi.org/10.1186/s40794-017-0052-2] [PMID: 28883979]

[17] Hill DR, Ryan ET. Management of travellers' diarrhoea. BMJ 2008; 337: a1746.

[http://dx.doi.org/10.1136/bmj.a1746] [PMID: 18838421]

[18] Leder K. Advising travellers about management of travellers' diarrhoea. Aust Fam Physician 2015; 44(1-2): 34-7.

[PMID: 25688957]

[19] Serichantalergs O, Ruekit S, Pandey P, Anuras S, Mason C, Bodhidatta $\mathrm{L}$, et al. Incidence of Campylobacter concisus and C. ureolyticus in traveler's diarrhea cases and asymptomatic controls in Nepal and Thailand. Gut Pathog 2017; 9: 47.

[http://dx.doi.org/10.1186/s13099-017-0197-6] [PMID: 28824712]

[20] Fillion K, Mileno MD. Cholera in travelers: Shifting tides in epidemiology, management, and prevention. Curr Infect Dis Rep 2015; 17(1): 455.

[http://dx.doi.org/10.1007/s11908-014-0455-4] [PMID: 25604481]

[21] Jiang ZD, DuPont HL. Etiology of travellers' diarrhea. J Travel Med 2017; 24(1): S13-6.

[http://dx.doi.org/10.1093/jtm/tax003] [PMID: 28521001]

[22] Michal Stevens A, Esposito DH, Stoney RJ, Hamer DH, FloresFigueroa J, Bottieau E, et al. Clostridium difficile infection in returning travellers. J Travel Med 2017; 24(3).

[http://dx.doi.org/10.1093/jtm/taw099] [PMID: 28355613]
[23] Leung AK, Kellner JD, Davies HD. Rotavirus gastroenteritis. Adv Ther 2005; 22(5): 476-87.

[http://dx.doi.org/10.1007/BF02849868] [PMID: 16418157]

[24] Simons MP, Pike BL, Hulseberg CE, Prouty MG, Swierczewski BE. Norovirus: New developments and implications for travelers' diarrhea. Trop Dis Travel Med Vaccines 2016; 2: 1.

[25] Barrett J, Brown M. Travellers' diarrhoea. BMJ 2016; 353: i1937.

[26] Thapa SS, Basnyat B. Chronic diarrhea in a traveler: Cyclosporiasis. Am J Med 2017; 130(12): e535-e36.

[http://dx.doi.org/10.1016/j.amjmed.2017.06.018]

[PMID: 28716461]

[27] Yoshikawa M, Ouji Y, Hirai N, Nakamura-Uchiyama F, Yamada $\mathrm{M}$, Arizono N, et al. Ancylostoma ceylanicum, novel etiological agent for traveler's diarrhea-report of four Japanese patients who returned from Southeast Asia and Papua New Guinea. Trop Med Health 2018; 46: 6.

[http://dx.doi.org/10.1186/s41182-018-0087-8] [PMID: 29563849]

[28] Camilleri M, Nullens S, Nelsen T. Enteroendocrine and neuronal mechanisms in pathophysiology of acute infectious diarrhea. Dig Dis Sci 2012; 57(1): 19-27.

[http://dx.doi.org/10.1007/s10620-011-1939-9] [PMID: 22001941]

[29] Muanprasat C, Chatsudthipong V. Cholera: Pathophysiology and emerging therapeutic targets. Future Med Chem 2013; 5(7): 78198.

[http://dx.doi.org/10.4155/fmc.13.42] [PMID: 23651092]

[30] Sack DA, Sack RB, Nair GB, Siddique AK. Cholera. Lancet 2004; 363(9404): 223-33.

[http://dx.doi.org/10.1016/S0140-6736(03)15328-7]

[PMID: 14738797]

[31] Mirhoseini A, Amani J, Nazarian S. Review on pathogenicity mechanism of enterotoxigenic Escherichia coli and vaccines against it. Microb Pathog 2018; 117: 162-9.

[http://dx.doi.org/10.1016/j.micpath.2018.02.032]

[PMID: 29474827]

[32] Field M. Intestinal ion transport and the pathophysiology of diarrhea. J Clin Invest 2003; 111(7): 931-43.

[http://dx.doi.org/10.1172/JCI200318326] [PMID: 12671039]

[33] Hoque KM, Chakraborty S, Sheikh IA, Woodward OM. New advances in the pathophysiology of intestinal ion transport and barrier function in diarrhea and the impact on therapy. Expert Rev Anti Infect Ther 2012; 10(6): 687-99.

[http://dx.doi.org/10.1586/eri.12.47] [PMID: 22734958]

[34] LaRocque R, Harris JB. Travelers' diarrhea: Clinical manifestations, diagnosis, and treatment. Available at: https://www. uptodate.com/contents/travelers-diarrhea-clinical-manifestationsdiagnosis-and-treatment(Accessed on September 30, 2018).

[35] Connor BA, Rogova M, Whyte O. Use of a multiplex DNA extraction PCR in the identification of pathogens in travelers' diarrhea. J Travel Med 2018; 25(1).

[http://dx.doi.org/10.1093/jtm/tax087] [PMID: 29394385]

[36] Connor BA. Multiplex PCR testing for travelers' diarrhea-friend or foe? Int J Infect Dis 2018; 66: 96-8.

[http://dx.doi.org/10.1016/j.ijid.2017.11.022] [PMID: 29175449]

[37] Hamer DH. Multiplex PCR for determining aetiology of travellers' diarrhoea: Too much information or too little? J Travel Med 2018; 25(1).

[http://dx.doi.org/10.1093/jtm/tax089] [PMID: 29394386]

[38] Vila J. New molecular diagnostic tools in traveller's diarrhea. J Travel Med 2017; 24: S23-S8.

[39] Leung AK, Darling P, Auclair C. Oral rehydration therapy- A review. J R Soc Health 1987; 107(2): 64-7.

[http://dx.doi.org/10.1177/146642408710700210] [PMID: 3108503]

[40] Leung AK, Robson WL. Acute diarrhea in children: What to do and what not to do. Postgrad Med 1989; 86(8): 161-4, 167-74.

[http://dx.doi.org/10.1080/00325481.1989.11704505]

[PMID: 2685791]

[41] Mera V, López T, Serralta J. Take traveller's diarrhoea to heart. Travel Med Infect Dis 2007; 5(3): 202-3.

[http://dx.doi.org/10.1016/j.tmaid.2006.11.001] [PMID: 17448951]

[42] Robson WL, Leung AK, Fick GH. Bloody diarrhea in hemolytic uremic syndrome. Child Nephrol Urol 1991; 11(4): 234-5. [PMID: 1777908]

[43] Robson WL, Leung AK, Trevenen CL, Brant R. Diarrheaassociated hemolytic uremic syndrome. Can Fam Physician 1993; 39: 2139-45. [PMID: 8219861] 
[44] Robson WL, Leung AK, Miller-Hughes DJ. Recurrent hemorrhagic colitis caused by Escherichia coli O157: H7. Pediatr Infect Dis J 1993; 12(8): 699-701.

[http://dx.doi.org/10.1097/00006454-199308000-00018] [PMID: 8414787]

[45] Robson WL, Leung AK. The hemolytic-uremic syndrome and Escherichia coli O157: H7 infection. Ann Intern Med 1993; 119(3): 249-50.

[http://dx.doi.org/10.7326/0003-4819-119-3-199308010-00025] [PMID: 8323100]

[46] Robson WL, Leung AK, Kaplan BS. Hemolytic-uremic syndrome. Curr Probl Pediatr 1993; 23(1): 16-33.

[http://dx.doi.org/10.1016/0045-9380(93)90027-A] [PMID: 8453889]

[47] Schwille-Kiuntke J, Enck P, Polster AV, Gaile M, Kremsner PG, Zanger P. Postinfectious irritable bowel syndrome after travelers' diarrhea- A cohort study. Neurogastroenterol Motil 2015; 27(8): 1147-55.

[http://dx.doi.org/10.1111/nmo.12601] [PMID: 26009981]

[48] Wagner A, Wiedermann U. Travellers' diarrhoea- Pros and cons of different prophylactic measures. Wien Klin Wochenschr 2009; 121: 13-8.

[http://dx.doi.org/10.1007/s00508-009-1228-1] [PMID: 19915810]

[49] Chow CM, Leung AK, Hon KL. Acute gastroenteritis: From guidelines to real life.Clin Exp Gastroenterol 2010; 3: 97-112.

[http://dx.doi.org/10.2147/CEG.S6554] [PMID: 21694853]

[50] Issenman RM, Leung AK. Oral and intravenous rehydration of children. Can Fam Physician 1993; 39: 2129-36.[PMID: 8219860]

[51] Leung AK, Sauve RS. Breast is best for babies. J Natl Med Assoc 2005; 97(7): 1010-9. [PMID: 16080672]

[52] Libman M; CATMAT. Summary of the Committee to Advise on Tropical Medicine and Travel (CATMAT) Statement on Travellers' Diarrhea. Can Commun Dis Rep 2015; 41(11): 272-84. [http://dx.doi.org/10.14745/ccdr.v41i11a03] [PMID: 29769922]

[53] Lääveri T, Sterne J, Rombo L, Kantele A. Systematic review of loperamide: No proof of antibiotics being superior to loperamide in treatment of mild/moderate travellers' diarrhea..Travel Med Infect Dis 2016; 14(4): 299-312.

[http://dx.doi.org/10.1016/j.tmaid.2016.06.006] [PMID: 27363327]

[54] Ericsson CD, Riddle MS. Should travel medicine practitioners prescribe antibiotics for self-treatment of travelers' diarrhea? J Travel Med 2018; $1 ; 25(1)$.

[http://dx.doi.org/10.1093/jtm/tay081] [PMID: 30184202]

[55] Pinos Y, Ruiz MI, Corsi Ó, Rada G. Is it worth adding loperamide to antibiotic treatment of traveler's diarrhea? Medwave 2017; 17: e6958.

[http://dx.doi.org/10.5867/medwave.2017.6958]

[PMID: 28549055]

[56] Heather CS. Travellers' diarrhoea. BMJ Clin Evid 2015; pii: 0901.

[57] Leung AK, Robson WL. Acute gastroenteritis in children: Role of anti-emetic medication for gastroenteritis-related vomiting. Paediatr Drugs 2007; 9(3): 175-84.

[http://dx.doi.org/10.2165/00148581-200709030-00006] [PMID: 17523698]

[58] Leung AK, Robson WL. In children with vomiting related to acute gastroenteritis, are antiemetic medications an effective adjunct to fluid and electrolyte therapy?: Part A: Evidence-based answer and summary.Paediatr Child Health 2008; 13(5): 391-4.

[http://dx.doi.org/10.1093/pch/13.5.391] [PMID: 19412369]

[59] Leung AK, Robson WL. In children with vomiting related to acute gastroenteritis, are antiemetic medications an effective adjunct to fluid and electrolyte therapy?: Part B: Clinical commentary. Paediatr Child Health 2008; 13(5): 393-4.

[http://dx.doi.org/10.1093/pch/13.5.393] [PMID: 19412370]

[60] De Bruyn G, Hahn S, Borwick A. Antibiotic treatment for travellers' diarrhoea. Cochrane Database Syst Rev 2000; (3): CD002242. [PMID: 10908534]

[61] McDonald LC. Effects of short- and long-course antibiotics on the lower intestinal microbiome as they relate to traveller's diarrhea. J Travel Med 2017; 24: S35-8.

[http://dx.doi.org/10.1093/jtm/taw084] [PMID: 28520993]

[62] DuPont HL. Systematic review: Prevention of travellers' diarrhoea. Aliment Pharmacol Ther 2008; 27(9): 741-51.

[http://dx.doi.org/10.1111/j.1365-2036.2008.03647.x]

[PMID: 18284650]
[63] Kogawa AC, Salgado HRN. Status of rifaximin: A review of characteristics, uses and analytical methods. Crit Rev Anal Chem 2018; 48(6): 459-66

[http://dx.doi.org/10.1080/10408347.2018.1447355]

[PMID: 29580065]

[64] Layer P, Andresen V. Review article: Rifaximin, a minimally absorbed oral antibacterial, for the treatment of travellers' diarrhoea. Aliment Pharmacol Ther 2010; 31(11): 1155-64. [http://dx.doi.org/10.1111/j.1365-2036.2010.04296.x] [PMID: 20331580]

[65] Bae JM. Prophylactic efficacy of probiotics on travelers' diarrhea An adaptive meta-analysis of randomized controlled trials. Epidemiol Health 2018; 40: e2018043.

[http://dx.doi.org/10.4178/epih.e2018043] [PMID: 30189723]

[66] Pinos Y, Castro-Gutiérrez V, Rada G. Are probiotics effective to prevent traveler's diarrhea? Medwave 2016; 16: e6807.

[http://dx.doi.org/10.5867/medwave.2016.6807]

[67] McFarland LV, Goh S. Are probiotics and prebiotics effective in the prevention of travellers' diarrhea: A systematic review and meta-analysis. Travel Med Infect Dis 2018: pii: S14778939(18)30258-8

[http://dx.doi.org/10.1016/j.tmaid.2018.09.007]

[68] Hasle G, Raastad R, Bjune G, Jenum PA, Heier L. Can a galactooligosaccharide reduce the risk of traveller's diarrhoea? A placebocontrolled, randomized, double-blind study. J Travel Med 2017; 24(5).

[http://dx.doi.org/10.1093/jtm/tax057] [PMID: 28931149]

[69] Evans DP. Non-pharmacotherapeutic interventions in travellersdiarrhoea (TD). J Travel Med 2018; 25: S38-S45.

[http://dx.doi.org/10.1093/jtm/tay013] [PMID: 29718436]

[70] Mokomane M, Kasvosve I, de Melo E, Pernica JM, Goldfarb DM. The global problem of childhood diarrhoeal diseases: Emerging strategies in prevention and management. Ther Adv Infect Dis 2018; 5(1): 29-43.

[http://dx.doi.org/10.1177/2049936117744429] [PMID: 29344358]

[71] Taylor DN, Hamer DH, Shlim DR. Medications for the prevention and treatment of travellers' diarrhea. J Travel Med 2017; 24: S17S22.

[http://dx.doi.org/10.1093/jtm/taw097] [PMID: 28520998]

[72] Ng QX, Ho CYX, Shin D, Venkatanarayanan N, Chan HW. A meta-analysis of the use of rifaximin to prevent travellers' diarrhoea. J Travel Med 2017; 24(5): 1-5. [http://dx.doi.org/10.1093/jtm/tax025] [PMID: 28498921]

[73] Neilson AA, Mayer CA. Cholera - Recommendations for prevention in travellers. Aust Fam Physician 2010; 39(4): 220-6.[PMID: 20372681]

[74] Ahmed T, Bhuiyan TR, Zaman K, Sinclair D, Qadri F. Vaccines for preventing enterotoxigenic Escherichia coli (ETEC) diarrhoea. Cochrane Database Syst Rev 2013; (7): CD009029.

[http://dx.doi.org/10.1002/14651858.CD009029.pub2] [PMID: 23828581]

[75] Torrell JM, Aumatell CM, Ramos SM, Mestre LG, Salas CM. Reduction of travellers' diarrhoea by WC/rBS oral cholera vaccine in young, high-risk travellers. Vaccine 2009; 27(30): 4074-7. [http://dx.doi.org/10.1016/j.vaccine.2009.04.025] [PMID: 19376179]

[76] López-Gigosos R, García-Fortea P, Reina-Doña E, Plaza-Martín E. Effectiveness in prevention of travellers' diarrhoea by an oral cholera vaccine WC/rBS. Travel Med Infect Dis 2007; 5(6): 380-4.

[http://dx.doi.org/10.1016/j.tmaid.2007.06.001] [PMID: 17983977]

[77] Wong KK, Burdette E, Mahon BE, Mintz ED, Ryan ET, Reingold AL. Recommendations of the Advisory Committee on Immunization Practices for use of cholera vaccine. MMWR Morb Mortal Wkly Rep 2017; 66(18): 482-85.

[http://dx.doi.org/10.15585/mmwr.mm6618a6] [PMID: 28493859]

[78] Mosley JF 2nd, Smith LL, Brantley P, Locke D, Como M. Vaxchora: The first FDA-approved cholera vaccination in the United States. PT 2017; 42(10): 638-40.[PMID: 29018300]

[79] Chen WH, Cohen MB, Kirkpatrick BD, Brady RC, Galloway D, Gurwith M, et al. Single-dose live oral cholera vaccine CVD 103$\mathrm{HgR}$ protects against human experimental infection with Vibrio cholerae O1 El Tor. Clin Infect Dis 2016; 62(11): 1329-35. [http://dx.doi.org/10.1093/cid/ciw145] [PMID: 27001804] 
[80] Kabir S. Critical analysis of compositions and protective efficacies of oral killed cholera vaccines. Clin Vaccine Immunol 2014; 21(9): 1195-205.

[http://dx.doi.org/10.1128/CVI.00378-14] [PMID: 25056361]

[81] Baik YO, Choi SK, Olveda RM, Espos RA, Ligsay AD, Montellano $\mathrm{MB}$, et al. A randomized, non-inferiority trial comparing two bivalent killed, whole cell, oral cholera vaccines (Euvichol vs Shanchol) in the Philippines. Vaccine 2015; 33(46): 6360-5.

[http://dx.doi.org/10.1016/j.vaccine.2015.08.075]

[PMID: 26348402]

[82] Bhattacharya SK, Sur D, Ali M, Kanungo S, You YA, Manna B, et al. 5 year efficacy of a bivalent killed whole-cell oral cholera vaccine in Kolkata, India: A cluster-randomised, double-blind, placebo-controlled trial. Lancet Infect Dis 2013; 13(12): 1050-6. [http://dx.doi.org/10.1016/S1473-3099(13)70273-1] [PMID: 24140390]

[83] Moro PL, Sukumaran L. Cholera vaccination: Pregnant women excluded no more.Lancet Infect Dis 2017; 17(5): 469-70. [http://dx.doi.org/10.1016/S1473-3099(17)30055-5] [PMID: 28161571]

[84] Ni Y, Springer MJ, Guo J, Finger-Baker I, Wilson JP, Cobb RR, et al. Development of a synthetic Vi polysaccharide vaccine for typhoid fever.Vaccine 2017; 35(51): 7121-6.

[http://dx.doi.org/10.1016/j.vaccine.2017.10.081]

[PMID: 29150208]

[85] Milligan R, Paul M, Richardson M, Neuberger A. Vaccines for preventing typhoid fever. Cochrane Database Syst Rev 2018; 5: CD001261. [PMID: 29851031]

[86] Ruiz-Palacios GM, Pérez-Schael I, Velázquez FR, Abate H, Breuer $\mathrm{T}$, Clemens SC, et al. Safety and efficacy of an attenuated vaccine against severe rotavirus gastroenteritis. N Engl J Med 2006; 354(1): $11-22$

[http://dx.doi.org/10.1056/NEJMoa052434] [PMID: 16394298]

[87] Vesikari T, Matson DO, Dennehy P, Van Damme P, Santosham M, Rodriguez Z, et al. Safety and efficacy of a pentavalent humanbovine (WC3) reassortant rotavirus vaccine. N Engl J Med 2006; 354(1): 23-33.

[http://dx.doi.org/10.1056/NEJMoa052664] [PMID: 16394299]

[88] Bhandari N, Rongsen-Chandola T, Bavdekar A, John J, Antony K, Taneja S, et al. Efficacy of a monovalent human-bovine (116E) rotavirus vaccine in Indian children in the second year of life.Vaccine 2014; 32 (Suppl 1): A110-6.

[http://dx.doi.org/10.1016/j.vaccine.2014.04.079] [PMID: 25091663]

[89] Praharaj I, Platts-Mills JA, Taneja S, Antony K, Yuhas K, Flores J, et al. Diarrheal etiology and impact of co-infections on rotavirus vaccine efficacy estimates in a clinical trial of a monovalent human-bovine (116E) oral rotavirus vaccine, Rotavac, India. Clin Infect Dis 2018 [Epub ahead of print] [http://dx.doi.org/10.1093/cid/ciy896] [PMID: 30335135]

[90] Goldsmid JM, Leggat PA. The returned traveller with diarrhoea. Aust Fam Physician 2007; 36(5): 322-7. [PMID: 17492065]

[91] Leung AK, Robson WL. Evaluating the child with chronic diarrhea. Am Fam Physician 1996; 53(2): 635-43. [PMID: 8629543]
[92] Giuntini S, Stoppato M, Sedic M, Ejemel M, Pondish JR, Wisheart $\mathrm{D}$, et al. Identification and characterization of human monoclonal antibodies for immunoprophylaxis against enterotoxigenic Escherichia coli infection. Infect Immun 2018; pii: IAI.00355-18. doi: 10.1128/IAI.00355-18. [Epub ahead of print]

[http://dx.doi.org/10.1128/IAI.00355-18]

[93] Rojas-Lopez M, Monterio R, Pizza M, Desvaux M, Rosini R. Intestinal pathogenic Escherichia coli: Insights for vaccine development. Front Microbiol 2018; 9: 440.

[http://dx.doi.org/10.3389/fmicb.2018.00440] [PMID: 29615989]

[94] Huang J, Duan Q, Zhang W. Significance of enterotoxigenic Escherichia coli (ETEC) heat-labile toxin (LT) enzymatic subunit epitopes in LT enterotoxicity and immunogenicity. Appl Environ Microbiol 2018; 84(15): pii: e00849-18.

[http://dx.doi.org/10.1128/AEM.00849-18] [PMID: 29802193]

[95] Walker RI, Wierzba TF, Mani S, Bourgeois AL. Vaccines against Shigella and enterotoxigenic Escherichia coli: A summary of the 2016 VASE Conference.Vaccine 2017; 35(49 Pt A): 6775-82. [http://dx.doi.org/10.1016/j.vaccine.2017.09.045]

[PMID: 28987444]

[96] Borde A, Ekman A, Larsson A, Carlin N, Holmgren J, Tobias J. Preparation and preclinical evaluation of a freeze-dried formulation of a novel combined multivalent whole-cell/B-subunit oral vaccine against enterotoxigenic Escherichia colidiarrhea. Eur J Pharm Biopharm 2016; 108: 18-24.

[http://dx.doi.org/10.1016/j.ejpb.2016.07.011] [PMID: 27485398]

[97] Isanaka S, Guindo O, Langendorf C, Matar Seck A, Plikaytis BD, Sayinzoga-Makombe N, et al. Efficacy of a low-cost, heat-stable oral rotavirus vaccine in Niger. N Engl J Med 2017; 376(12): 112130.

[http://dx.doi.org/10.1056/NEJMoa1609462] [PMID: 28328346]

[98] Mitra M, Shah N, Ghosh A, Chatterjee S, Kaur I, Bhattacharya N, et al. Efficacy and safety of vi-tetanus toxoid conjugated typhoid vaccine (PedaTyph ${ }^{\mathrm{TM}}$ ) in Indian children: School based cluster randomized study. Hum Vaccin Immunother 2016; 12(4): 939-45 [http://dx.doi.org/10.1080/21645515.2015.1117715] [PMID: 26901576]

[99] Sack, D.A., Zhang, W. Multiepitope fusion antigens and vaccines and their use in treatment of enterogenic diarrhea. US20160317638 (2016).

[100] Savkovic, S., Roy, H.K. Prophylaxis and treatment of enteropathogenic bacterial infection. US20140057993 (2014).

[101] Savarino, S.J. Adhesin as immunogen against enterotoxigenic Escherichia coli. US20150266932 (2015).

[102] Rao, D.R., Kankan, R.N., Phull, M.S., Ghagare, M. Rifaximin. US20160374999 (2016)

[103] Ghagare, M.G., Saroj, S.P., Rao, D.R., Kankan, R.N. Rifaximin complexes. US20180289817 (2018).

[104] Driessen, W.E. Composition and methods for treating traveler's diarrhea. US20180296628 (2018).

[105] Cheng, S.X. Materials and methods for prevention and treatment of diarrhea and inflammation of the gastrointestinal tract. US20180271903 (2018)

[106] Lefevre, J.M., Renaud, G., Le Guern, M.E. Composition and methods for preventing infections. US20180153947 (2018). 